\title{
Climate change assessment for Mediterranean agricultural areas by statistical downscaling
}

\author{
L. Palatella ${ }^{1}$, M. M. Miglietta ${ }^{1}$, P. Paradisi ${ }^{1}$, and P. Lionello ${ }^{2}$ \\ ${ }^{1}$ ISAC-CNR, Strada Prov. Lecce-Monteroni km 1, 200, 73100, Lecce, Italy \\ ${ }^{2}$ Dipartimento di Scienze dei Materiali - Università del Salento, Strada Prov. Lecce-Monteroni km 1, 200, 73100, Lecce, Italy
}

Received: 12 November 2009 - Revised: 31 May 2010 - Accepted: 16 June 2010 - Published: 30 July 2010

\begin{abstract}
In this paper we produce projections of seasonal precipitation for four Mediterranean areas: Apulia region (Italy), Ebro river basin (Spain), Po valley (Italy) and Antalya province (Turkey). We performed the statistical downscaling using Canonical Correlation Analysis (CCA) in two versions: in one case Principal Component Analysis (PCA) filter is applied only to predictor and in the other to both predictor and predictand. After performing a validation test, CCA after PCA filter on both predictor and predictand has been chosen. Sea level pressure (SLP) is used as predictor. Downscaling has been carried out for the scenarios A2 and B2 on the basis of three GCM's: the CCCma-GCM2, the Csiro-MK2 and HadCM3. Three consecutive 30-year periods have been considered. For Summer precipitation in Apulia region we also use the $500 \mathrm{hPa}$ temperature (T500) as predictor, obtaining comparable results. Results show different climate change signals in the four areas and confirm the need of an analysis that is capable of resolving internal differences within the Mediterranean region. The most robust signal is the reduction of Summer precipitation in the Ebro river basin. Other significative results are the increase of precipitation over Apulia in Summer, the reduction over the Po-valley in Spring and Autumn and the increase over the Antalya province in Summer and Autumn.
\end{abstract}

\section{Introduction}

In the last few years the use of very powerful computers has permitted the development of more and more sophisticated climatic models. These models, including the dynamics of both atmosphere and oceans, are generally referred to as Global Climate Models (GCM). Though recent improve-

Correspondence to: M. M. Miglietta (m.miglietta@isac.cnr.it) ments of computational power are producing global simulation with progressively higher resolution, for most of the available simulations the resolution is of some degrees of latitude and longitude (Randall et al., 2007). To check the validity of these models, one performs a control run simulation (CTR) obtained with the parameters corresponding to the atmospheric composition measured in the 20th century. If the obtained results are statistically similar to the historical records of pressure, temperature, humidity, precipitation, then the model dynamics is a reliable approximation of the real climate dynamics.

The future climate is computed by the same GCM using the atmospheric composition predicted in the different scenarios defined by the IPCC in the Special Report Emission Scenarios (SRES) (IPCC, 2001). The climatic projection obtained in this way has the spatial resolution given by the grid of the GCM. Though the amount of computational resources available for the simulation is increasing, the grid spacing in mid-latitude regions is still some hundreds of kilometers. In any case, even the finest available resolution is sufficient for describing the pressure and temperature fields, but it is not suitable for precipitation (von Storch et al., 1993; von Storch and Zwiers, 1999; Zorita and von Storch, 1999).

For this reason, regional downscaling is crucial for describing the precipitation climate of the Mediterranean region, which is characterized by very large space variability. This is produced by steep morphological and complicated land-sea patterns (see Lionello et al., 2006 for a review), and by its location in a transitional region from the mid-latitude mild and wet climate in the north to the tropical hot and dry climate in the south. Therefore, Mediterranean Winter precipitation is affected by mid-latitude regimes, such as the North Atlantic Oscillation (NAO) and the East Atlantic (EA) pattern (Trigo et al., 2006), and by tropical phenomena like El Niño Southern Oscillation (ENSO). Mediterranean Summer precipitation has been connected with both the Asian and the African monsoon and with strong geopotential blocking

Published by Copernicus Publications on behalf of the European Geosciences Union. 
anomalies over central Europe (Alpert et al., 2006). Processes active at a wide range of spatial and temporal scales result in many climate types and great spatial variability. These processes are induced by the complex morphology (e.g. the effect of the Alpine chains on the air-flow, the presence of the Mediterranean Sea itself) and by the effect of anthropogenic and natural aerosols (Lionello et al., 2006). Statistical downscaling methods, as those applied in this study, are useful tools for the simulation of the effects of these local processes and features.

In the Mediterranean region the trend in precipitation intensity is generally negative but rarely significant (Brunetti et al., 2004, 2006), and with high spatial and monthly variability even in a limited region (Gonzales-Hidalgo et al., 2009). Other authors (Jacobeit et al., 2007; Xoplaki, 2002; Xoplaki et al., 2004) reported a decrease in precipitation in the Mediterranean area during the second half of the 20th century, specifically a decrease of Winter precipitation. This decrease is prevalently attributed to the positive phase on the NAO in the last decades (Hurrell, 1995). However, the decrease of precipitation during Winter of the last decades is not reproduced by the global climate models.

GCM's generally agree on a substantial future drying of the Mediterranean region in all the different scenarios, especially in the warm season, with a precipitation decrease exceeding 25-30\% (Giorgi and Lionello, 2008). The projected reduction of precipitation is, however, not uniform in the whole region. Some models predict an increase of precipitation during Winter over some areas of the northern Mediterranean basin, particularly the Alps, and during Summer in the Middle East. Therefore, it is important to further investigate the detailed spatial distribution of the precipitation change and its actual evolution by suitable downscaling techniques. Note that decrease and irregularity of precipitation are important factors that critically contribute to the large sensitivity of the Mediterranean region to climate change (Giorgi, 2006).

There are two main categories of downscaling techniques: dynamical and statistical downscaling. Dynamical downscaling is performed using climate models over a limited domain with high resolution (nowadays $20-50 \mathrm{~km}$ ) and using the results of a GCM as initial and boundary conditions.

Several authors developed statistical downscaling techniques for climatic predictions in order to provide scenarios for selected small regions or complement the results of dynamical models. Statistical downscaling represents a computer-wise cheap method that is very suitable for describing seasonal climate variability at regional and local scale. It can contribute to reach an higher confidence on future projections, and can be adapted for a wide range of applications. Statistical downscaling is based on statistical relationships linking regional climate variables (predictand) to large-scale atmospheric variables (predictor). Such links are determined during an observational period and are verified using independent data outside this period. The identified statistical relationships are then used for computing fu- ture climate projections. Statistical downscaling has been successfully applied to precipitation climate change in the Mediterranean region already in the 90's (e.g., von Storch et al., 1993; Corte-Real et al., 1995). The STARDEX project (Goodess, 2005) included a large set of statistical downscaling studies. A recent example of statistical downscaling for the wet season precipitation is provided by Hertig and Jacobeit (2008) that reports a contrasting behavior for the period 2071-2100 compared to 1990-2019. The wet season is projected to become shorter but wetter in the western and northern Mediterranean regions, while precipitation changes are mainly negative in the eastern and southern parts of the basin.

In this study we adopt the sea level pressure (SLP) or the $500 \mathrm{hPa}$ temperature (T500) as large scale predictor, and precipitation as predictand and we compare the performance of the Canonical Correlation Analysis (CCA) after applying the Principal Component Analysis (PCA) filter to the predictor and the CCA after PCA filtering applied to both predictor and predictand.

The datasets used in this study are the SLP EMULATE project, the ERA-40 reanalysis of ECMWF for T500 and the Climate Research Unit (CRU) of East Anglia University monthly precipitation dataset. We downscale the predictions relative to the SRES A2 and B2 of three different GCM's: a) the CSIRO-Mk2 model from the Commonwealth Scientific and Industrial Research Organization (briefly Csiro), b) the HADCM3 model developed at the Hadley Centre for Climate Prediction and Research UK (briefly Hadley), c) the GCM2 model developed at the Canadian Center for Climate Modeling and Analysis, CCCma (hereafter Canadian).

The focus in the present study is on the estimation of precipitation trends in climate change scenarios. This analysis is particularly relevant for the economy of the Mediterranean region, as rainfall variability represents a major source of risk for crop systems and changes in the pluviometric regimes can significantly affect the agriculture of entire regions (Vasiliades et al., 2009).

In this study we followed the STARDEX (Goodess, 2005) suggestion of applying CCA methods locally with the following peculiarities: that the analysis is extended to the whole year, considering independently changes in single seasons (Dec-Jan-Feb, Mar-Apr-May, Jun-Jul-Aug, Sep-OctNov); that we use a set of relatively small targets, which are identified as major agricultural areas; and that we analyze each of them separately with the same procedure.

The paper outline is the following. In Sect. 2 we describe the datasets and the GCM's used. In Sect. 3 we briefly introduce the statistical techniques used and we compare each other. In Sect. 4 we show the results of the downscaling of precipitation relative to four different Mediterranean areas for different scenarios. Finally, in Sect. 5 conclusions are summarized. 


\section{Data}

Data include predictor and predictand.

\subsection{Predictor: SLP from EMULATE dataset}

The Sea Level Pressure (SLP) EMULATE dataset (Ansell et al., 2006) is based on daily average sea level pressure values for the period from January 1850 to December 2003. The data cover the region from $70^{\circ} \mathrm{W}-70^{\circ} \mathrm{N}$ (top left corner) to $50^{\circ} \mathrm{E}-25^{\circ} \mathrm{N}$ (bottom right corner). The grid is $5^{\circ} \times 5^{\circ}$ in latitude and longitude. This means that at each time step the dataset consists of 250 SLP values. The dataset covers the region involved in the North Atlantic Oscillation (NAO) and in the dynamical features responsible for precipitation in Europe.

\subsection{Predictor: T500 from ECMWF}

The ERA-40 monthly averaged $500 \mathrm{hPa}$ temperature reanalysis (Uppala et al., 2005) is retrieved from the European Center for Medium-Range Weather Forecasts (ECMWF) data server for the period from 1958 to 2001 . The global data are distributed on a Gaussian grid $320^{\circ} \times 160^{\circ}$ with a resolution of approximately $1.125^{\circ} \times 1.125^{\circ}$. To obtain a resolution comparable with that of SLP, we upscale the T500 data on the same grid points of the EMULATE dataset. The upscaling is recommended because in this way the resolution of both predictors is comparable with that of the GCM data available for future scenarios.

\subsection{Predictand: precipitation from Climate Research Unit (CRU) of East Anglia University ${ }^{1}$}

The predictand is obtained from the monthly averaged precipitation dataset called CRU TS 2.1 (Mitchell and Jones, 2005) for the period from January 1901 to December 2002 for a total of 102 years. From this dataset we extract the data corresponding approximatively to four areas of agricultural interest in the Mediterranean region: Apulia region (Italy, 22 points), Ebro river basin (Spain, 24 points), Povalley (Italy, 30 points), Antalya province (Turkey, 6 points). Data represent average values on a square grid of $0.5^{\circ} \times 0.5^{\circ}$. The location of the points is shown in Fig. 1. However, it should be considered that the data coverage is scarse in some periods (e.g. during the second world war), thus the high resolution of the dataset is only nominal in those years, especially in the smallest regions.

\subsection{Global Climate Model data}

We retrieve from the International Panel on Climate Change IPCC-Data server ${ }^{2}$ the SLP and T500 projections relative

\footnotetext{
$1_{\text {www.cru.uea.ac.uk }}$

${ }^{2}$ http://www.mad.zmaw.de/IPCC_DDC/html/ddc_gcmdata.html
}

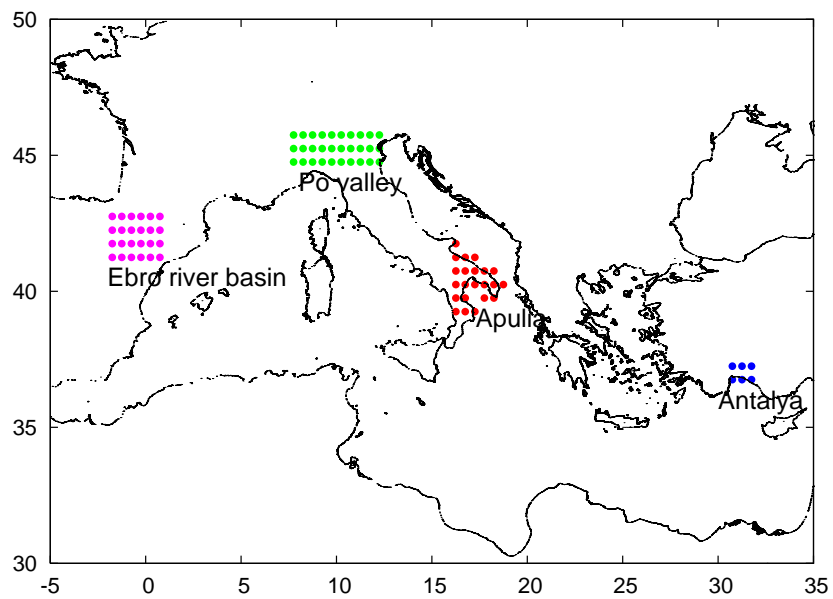

Fig. 1. Points of CRU dataset used for downscaling. The four areas considered are indicated.

to the A2 and B2 scenarios of the Third Assessment Report (TAR) for the following GCM's models: a) the Commonwealth Scientific and Industrial Research Organization, CSIRO, model CSIRO-Mk2 (briefly Csiro), b) the Hadley Centre for Climate Prediction and Research UK, HCCPR, model HADCM3 (Hadley), c) the Canadian Center for Climate Modeling and Analysis, CCCma, model CGCM2 (Canadian). The CSIRO-Mk2 model is a spectral model with R21 horizontal resolution (approximately $3.2^{\circ}$ in latitude $\times 5.6^{\circ}$ in longitude) and 9 vertical $\sigma$-levels in the atmosphere (Watterson et al., 1995) (top level at $\sigma=0.021$ ), including a slab ocean sub-model with 21 levels. HadCM3 (Gordon et al., 2000) is a coupled model, with the atmospheric component having 19 levels (top at $10 \mathrm{hPa}$ ) with a horizontal resolution of $2.5^{\circ}$ in latitude and $3.75^{\circ}$ in longitude. This is equivalent to a surface resolution of $417 \mathrm{~km} \times 278 \mathrm{~km}$ at the Equator, reducing to $295 \times 278 \mathrm{~km}$ at $45^{\circ}$ of latitude (comparable to a spectral resolution of T42). The oceanic component has 20 levels with a horizontal resolution of $1.25^{\circ} \times 1.25^{\circ}$. The atmospheric component of CGCM2 (Flato et al., 2000) consists of a spectral model with a spectral resolution T32 (horizontal resolution of approximately $3.75^{\circ} \times 3.75^{\circ}$ ). It includes 10 vertical levels (top level at $\eta=0.012$, McFarlane et al., 1992). The oceanic component presents a horizontal resolution of $1.875^{\circ} \times 1.875^{\circ}$ with 29 vertical levels.

The choice of the models is motivated by the fact that for all of them the Control Run from 1961 to 1990 is available together with the A2 and B2 scenarios from 1991 to 2100. The data are available on a $64 \times 56$ grid for Csiro, $96 \times 73$ for Hadley and $97 \times 48$ for Canadian. In all cases the GCM predictions are interpolated on the same grid of the EMULATE data in order to project them on the canonical patterns obtained from the statistical model (see Appendix A for the interpolation technique). 


\section{The statistical techniques}

In this study we compare the performance of Canonical Correlation Analysis (CCA) applied in two variants, after performing Principal Component Analysis (PCA) filtering on predictor and on both predictor and predictand. These techniques are well known, see for example von Storch and Zwiers (1999), and we briefly describe them in Appendix A, where we refer the reader for the notation used in the rest of this paper. CCA after PCA prefiltering remains a consolidated and well established method for downscaling, currently used for climate change studies (e.g. Hertig and Jacobeit, 2008). The CCA methods relies on the presence of a linear link between regional precipitation and the large scale predictor field (in this study SLP and $500 \mathrm{hPa}$ temperature) and of the invariance of such link in the projected climate, which is assumed to be a small perturbation of the present condition. This technique is consolidated and the purpose of this study is not methodological, but it aims to provide a focalized information on target areas of agricultural interest, with seasonal resolution, in order to investigate the dependence of the climate change signal in space and time.

\subsection{Testing the techniques}

Several studies on the applications of these techniques in climatology are available in the literature (see for example von Storch et al., 1993; von Storch and Zwiers, 1999; Zorita and von Storch, 1999; Lionello et al., 2003). Here we briefly explain the logical scheme of the downscaling procedure. From an observed time series of predictors (in our case the mean seasonal SLP field or, just in one case, the T500 field) and predictand (the accumulated seasonal precipitation) we establish, by means of a training procedure, a statistical model, which provides a tool for the computation of the predictand from the predictors. We make the hypothesis that this statistical model remains valid also in the SRES climate scenarios and compute the predictands using the predictors extracted from the GCM climate projections.

The choice of the time resolution in statistical downscaling is a crucial point. If we would perform the CCA with a time interval $\Delta t=1$ day, we would obtain Canonical Patterns for the predictor with horizontal scale that can be as small as few tens of kilometers, because on such time scale the precipitation is mainly due to low pressure systems close to the region affected with the rainfall. In this case, the spatial scale of the predictor, $F_{x}$, would be finer than the resolution of GCM simulations and it would be impossible to adequately identify the predictor structure in the GCM outputs. As we decrease time resolution, CP's with progressively larger spatial scales are likely to result from the analysis. In this study we perform the downscaling procedures on average seasonal precipitation grouping together Winter (DJF, Dec-Jan-Feb), Spring (MAM, Mar-Apr-May), Summer (JJA, Jun-Jul-Aug) and Autumn (SON, Sep-Oct-Nov) months, so that the large scale patterns responsible for variability at such long scale are likely to be reproduced by GCM's.

The data have been analyzed with two different versions of Canonical Correlation Analysis: a) CCA after a PCA filtering on the predictors (CCA-PCAX) and on both predictors and predictands (CCA-PCAXY). In the case CCA-PCAX the PCA filtering retains 15 eigenvectors describing more than $95 \%$ of the variance. The same happens for the predictors in the case CCA-PCAXY while the predictands were filtered retaining only 3 eigenvectors (describing more than $95 \%$ of variance). As explained in von Storch and Zwiers (1999) (p. 304) there are several criteria for the choice of the number of PCA eigenvectors to be retained. A different approach, that von Storch and Zwiers (1999) however do not suggest, is to consider the "knee" in the eigenvalues spectrum and to retain only eigenvalues considerably greater than the asymptotic spectrum. We perform the calculation using also this criterium obtaining comparable or worse results. All the predictions by means of CCA are calculated using the first two canonical conjugates that result as the only ones with eigenvalues larger than the others. Using a larger number of canonical conjugates does not improve the results.

The model has been validated splitting the historical time series in two periods of the same length. As the whole series is 102 years long, we have two 51 years long periods, respectively 1901-1951, 1952-2002. In a first time we use the first period as the training series, in order to build the statistical model, and the second one as the validation one. After that we change the roles of the two periods performing training on the second half of the years and validation on the first one. The agreement between the original data and the predicted ones during the validation period is used to assess the quality of the methods. The results of the test performed over the four selected areas is shown in Table 1. The mean relative error in the prediction during the validation period is defined as $\sigma / \bar{p}$, with

$\sigma^{2}=\frac{\sum_{i=1}^{\tau} \sum_{j=1}^{N}\left(\mathcal{Y}_{j}(i)-\tilde{\mathcal{Y}}_{j}(i)\right)^{2}}{\tau N} ; \quad \bar{p}=\frac{\sum_{i=1}^{\tau} \sum_{j=1}^{N} \mathcal{Y}_{j}(i)}{\tau N}$,

where $N$ denotes the number of points in each area, $\tau$ the number of time steps, and $\mathcal{Y}_{j}(i)$ and $\tilde{\mathcal{Y}}_{j}(i)$ represent the CRU and downscaled precipitation (at point $j$ and time $i$ ), respectively ( $\sigma^{2}$ is the mean squared error as discussed in von Storch and Zwiers (1999), p. 396. In this paper we divide it by the mean observed value $\bar{p}$, thus obtaining a relative error).

Columns labelled with "rev" stand for the training period on the second half and validation on the first 51 years. Bold numbers indicate the best value among the techniques. Notice that the best score for "reverse" experiments are considered separately from direct validation tests. There are 18 cases where CCA-PCAXY is the best choice and 14 
Table 1. Values of mean relative error for the different techniques and for the four areas under consideration during the 51 year long validation period. Columns labelled with "rev" refer to training on the second half of the period and validation on the first one. Bold numbers indicate best scores.

\begin{tabular}{lcrcc}
\hline Season & \multicolumn{2}{c}{ CCA-PCAX } & CCA-PCAXY \\
& \multicolumn{5}{c}{ rev } & rev \\
\hline \multicolumn{5}{c}{ Apulia } \\
DJF & 0.352 & $\mathbf{0 . 3 5 1}$ & $\mathbf{0 . 3 0 9}$ & 0.362 \\
MAM & 0.367 & 0.345 & $\mathbf{0 . 3 2 1}$ & $\mathbf{0 . 3 0 7}$ \\
JJA & 0.613 & $\mathbf{0 . 5 4 0}$ & $\mathbf{0 . 5 7 5}$ & 0.624 \\
SON & 0.361 & 0.352 & $\mathbf{0 . 3 6 0}$ & $\mathbf{0 . 3 0 1}$ \\
\multicolumn{5}{c}{} \\
DJF & 0.355 & 0.374 & $\mathbf{0 . 3 3 5}$ & $\mathbf{0 . 3 1 6}$ \\
MAM & $\mathbf{0 . 2 8 7}$ & 0.307 & 0.301 & $\mathbf{0 . 2 8 9}$ \\
JJA & 0.405 & $\mathbf{0 . 3 7 4}$ & $\mathbf{0 . 4 0 2}$ & 0.397 \\
SON & 0.435 & 0.331 & $\mathbf{0 . 3 8 3}$ & $\mathbf{0 . 3 2 9}$ \\
\multicolumn{5}{c}{ Po valley } \\
DJF & 0.428 & 0.449 & $\mathbf{0 . 4 0 1}$ & $\mathbf{0 . 3 9 3}$ \\
MAM & $\mathbf{0 . 4 4 3}$ & $\mathbf{0 . 4 4 4}$ & 0.468 & 0.476 \\
JJA & 0.299 & 0.292 & $\mathbf{0 . 2 8 5}$ & $\mathbf{0 . 2 7 9}$ \\
SON & $\mathbf{0 . 4 8 9}$ & $\mathbf{0 . 4 1 3}$ & 0.521 & 0.440 \\
\multicolumn{5}{c}{ Antalya } \\
DJF & 0.425 & 0.313 & $\mathbf{0 . 4 0 2}$ & $\mathbf{0 . 3 0 8}$ \\
MAM & $\mathbf{0 . 4 9 2}$ & $\mathbf{0 . 3 5 3}$ & 0.513 & 0.382 \\
JJA & $\mathbf{0 . 5 6 2}$ & $\mathbf{0 . 9 3 4}$ & 0.749 & 0.961 \\
SON & $\mathbf{0 . 4 6 5}$ & $\mathbf{0 . 4 4 8}$ & 0.472 & 0.452 \\
\hline
\end{tabular}

where CCA-PCAX is better. Even if a PCA filtering on predictands eliminates the small scale precipitation fluctuations, which are probably not correlated with the large scale circulations, the two methods produce similar results apart from two cases, both in JJA (thus the specific results should be taken with care). ${ }^{3}$

With the exception of Summer precipitation, the best results refer to Ebro river basin, then Apulia; the worst results are obtained in the Po Valley and in the Antalya province. In Summer all techniques lead to worse results with the exception of Po Valley, where the error becomes considerably smaller.

In the literature several methods are used to assess the validity of the statistical downscaling (see von Storch and Zwiers, 1999 for a review). One approach is the use of the Pearson correlation $r$. Nevertheless, this approach in some cases may lead to misleading results because the short time oscillations of the predictand may be not correlated to the large scale dynamics of the predictor, so this fact will lead

\footnotetext{
${ }^{3}$ The low impact of Principal Component Analysis filter on final results may be partially due to the change of coverage of stations, used to produce the CRU analysis, during the analyzed period.
}
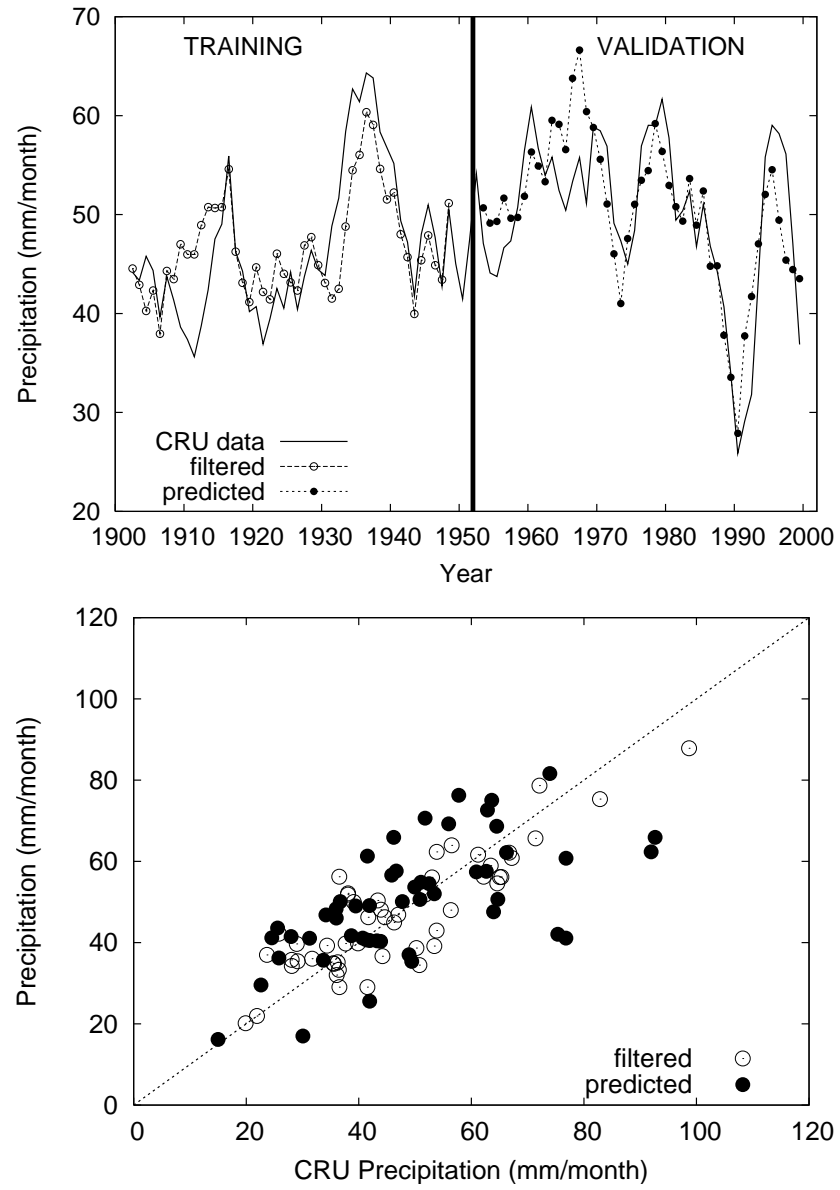

Fig. 2. Ebro river basin: comparison between downscaled and CRU precipitation in Winter (DJF). The top panel shows the 5-year running mean of the spatial average for the CRU dataset and downscaled precipitation during both training (first 51 years) and validation period (last 51 years). The bottom panel shows the scatter plot of CRU versus downscaled spatially averaged precipitation. Empty circles refer to the training period, filled circles to the validation one.

to low values of the correlation coefficient even if the larger time behavior of the real and predicted signal are correlated. For this reason we decided to use the average error to evaluate the performance of the different downscaling techniques. For any case in Table 2 we report the value of the Pearson correlation $r$ in the CCA-PCAXY case. Values of $r$ greater than 0.36 are statistically significant with 49 degrees of freedom (51 time step -2$)$ for $p<0.01$. The values reported for Apulia and Ebro river basin are significant for DJF, MAM and SON. For Po Valley only DJF and JJA reverse are significant while for Antalya region only DJF reverse is significant.

Figure 2 (obtained with the CCA-PCAXY method) shows the average value of precipitation over the whole Ebro river basin during the Winter season (the upper panel shows the time series of the 5-year running average of precipitation, 

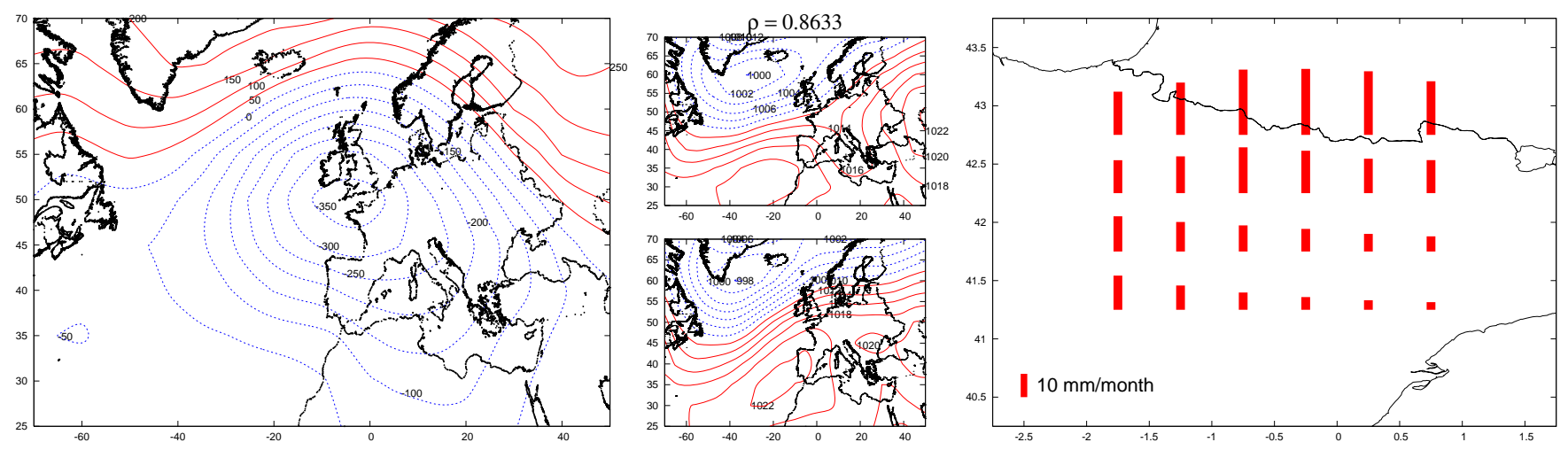

Fig. 3. First CP's obtained using CCA-PCAXY on Ebro river basin precipitation. The left figure represents the SLP CP measured in Pa (blue contours refer to negative values, red ones to positive). The two figures in the center represent the average winter SLP (hPa) plus (the top) and minus (bottom) the SLP CP (blue contours refer to values lower than $1013 \mathrm{hPa}$, red ones to higher values). These figures show the actual pattern of SLP when the coefficient of the CP is positive or negative. On the right we have the CP of precipitation measured in mm/month.

Table 2. Pearson correlation $r$ for predicted and observed precipitation in the validation period for the CCA-PCAXY technique. Parameters are the same as in Table 1; "rev" refer to training on the second half and validation on the first one.

\begin{tabular}{|c|c|c|}
\hline Season & Pearson $r$ & rev \\
\hline \multicolumn{3}{|c|}{ Apulia } \\
\hline DJF & 0.549 & 0.400 \\
\hline MAM & 0.484 & 0.423 \\
\hline JJA & 0.327 & 0.103 \\
\hline SON & 0.416 & 0.462 \\
\hline \multicolumn{3}{|c|}{ Ebro river basin } \\
\hline DJF & 0.606 & 0.675 \\
\hline MAM & 0.471 & 0.435 \\
\hline JJA & 0.338 & 0.351 \\
\hline SON & 0.452 & 0.492 \\
\hline \multicolumn{3}{|c|}{ Po Valley } \\
\hline DJF & 0.628 & 0.613 \\
\hline MAM & 0.080 & 0.019 \\
\hline JJA & 0.326 & 0.420 \\
\hline SON & -0.150 & -0.036 \\
\hline \multicolumn{3}{|c|}{ Antalya } \\
\hline DJF & 0.343 & 0.364 \\
\hline MAM & -0.016 & 0.068 \\
\hline JJA & 0.203 & 0.048 \\
\hline SON & 0.270 & 0.276 \\
\hline
\end{tabular}

the lower panel shows a scatter plot of CRU versus downscaled precipitation for individual years). The overall agreement between the CRU data and the downscaled precipitation during the validation period (1952-2002) demonstrates the effectiveness of the technique.
Figure 3 shows the first $\mathrm{CP}$ for predictors and predictands obtained on Ebro river basin DJF precipitation using the CCA-PCAXY method (the results with CCA-PCAX, not shown, are very similar). Note that using CCA-PCAXY method the correlation $\rho_{x y}$ between the time coefficients $\beta_{x}(t), \beta_{y}(t)$ is much more stable than using CCA-PCAX, meaning that its computation during the validation confirms the value obtained during the training. Nevertheless, CP's and predictions obtained by the two techniques are quite similar and reliable results could be obtained using both methods. Incidentally, we notice that the pattern of SLP associated with positive precipitation anomaly (top small panel in the center of the figures) presents for both the techniques a wide trough over the central Mediterranean Sea east of the Iberian peninsula, suggesting that this configuration is responsible for Winter precipitation on the Ebro river basin.

In general precipitation is more difficult to predict in JJA than in DJF. In order to get an independent qualitative evaluation and provide an interpretation in terms of synoptic features, the downscaling using the $500 \mathrm{hPa}$ temperature (T500) as predictor has been attempted over Apulia region. In fact, we expect that in southern Mediterranean areas Summer precipitation are strongly correlated to small scale convective events (Saaroni and Ziv, 2000) due to diurnal heating and to the presence of cold air in the middle troposphere. The T500 data from the ERA-40 archive were upscaled to the same grid used in the EMULATE project. Unfortunately these data cover only the period from 1958 to 2001, so that the value of the correlation is not directly comparable to that obtained using SLP as predictor. Figure 4 shows that the first CP for T500 presents a cold air mass over southern Italy. This configuration is consistent with the SLP first CP resulting from the previous CCA-PCAXY analysis, which presents a positive SLP anomaly over northern Europe and a negative SLP anomaly over southern Italy. This configuration strenghtens subsidence in northern Europe while favors ascending motion over the Mediterranean Sea. 

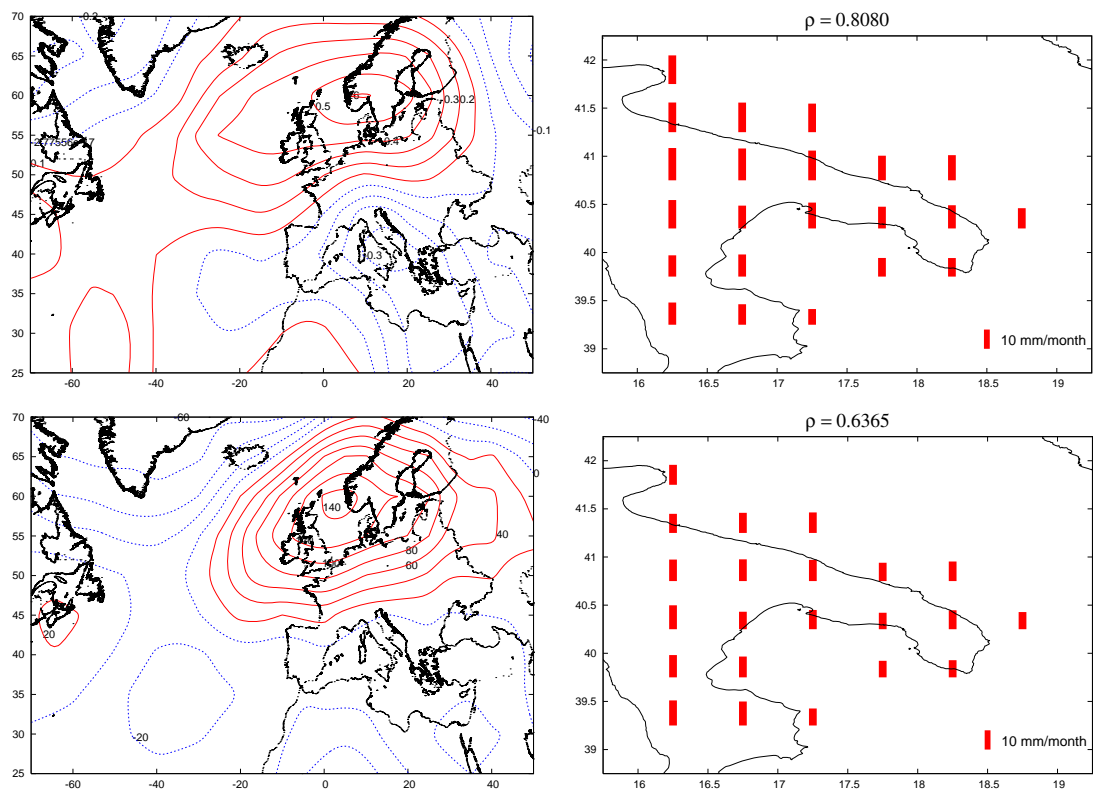

Fig. 4. Comparison between the first CP's for JJA Apulia precipitation using $T$ at $500 \mathrm{hPa}$ (top) and SLP (bottom) as predictors. On the left the CP T500 $(\mathrm{K})$ and SLP $(\mathrm{Pa})$ are shown (blue contours refer to negative CP values, red ones to positive). The right figures show the corresponding precipitation $\mathrm{CP}$ in $\mathrm{mm} /$ month.

\section{Downscaling of Global Climatic Models (GCM) projections}

The CCA-PCAXY technique has been used for downscaling precipitation over the four different areas for the whole 1961-2100 period and for both A2 and B2 SRES. Besides the CTR period (1961-1990) three 30 year long sub-periods are considered: 2011-2040 (I), 2041-2070 (II) and 20712100 (III). For each subperiod the average precipitation is computed over the four areas and the statistical significance of differences with respect to the CTR is evaluated using the Mann-Whitney test on ranks (Hollander and Wolfe, 1973). In this test the individual ranks calculated on two series of data are summed within each series, then the difference between the two totals are compared under the null hypothesis that the two series were obtained from the same distribution. If the difference is larger than the threshold value (the $95 \%$ confidence level has been adopted in this study), the null hypothesis is rejected and the two series are considered significantly different.

Figures 5, 6, 7, and 8 show for each season (DJF, MAM, JJA, SON from top to bottom) and for Apulia, Ebro river basin, Po valley and Antalya province, respectively, the mean value of precipitation over the 30 years of CTR, I, II, III periods. The average CRU value for the CTR period (on the left side of each panel) and the one standard deviation error bar for each value are also shown. Points connected with solid red line refer to A2 SRES, while those connected with dashed blue lines refer to B2 SRES. In each figure the circles refer to Canadian GCM, the triangles to Csiro and the reverse-triangles to Hadley Centre GCM. Filled and larger symbols denote statistically significant differences with respect to the CTR.

\subsection{GCM validation and SLP field problem}

Our analysis is potentially affected by the so-called SLP field problem (e.g., Trigo and Palutikof, 2001), that is the inability of models to reproduce the correct average value of SLP in the CTR, especially the tendency to overestimate the difference between the Azores' high and the low over Iceland. If the GCM fails to predict the correct mean value in the CTR, this leads to serious doubts about the capacity of the same GCM to simulate precipitation. From the statistical downscaling perspective this is a very serious problem, because precipitation over Europe is strongly correlated to the difference between Azores' high and Iceland low (linked to the NAO index). A wrong SLP mean field would prevent the statistical downscaling from computing the correct mean precipitation. However, in literature, it is reported that, despite this serious bias, the GCM's are able to capture the correct variability of SLP.

With particular regard to the three GCM's used in this paper in literature one finds several papers dealing with the validation of the SLP predicted in the CTR.

It is known that the CCCma (Canadian GCM) (Flato et al., 2000; Flato and Boer, 2001) simulates the mean sea level pressure quite realistically, with the climatological features faithfully captured (McFarlane et al., 1992). However, some deficiencies are documented: for example, SLP in high 

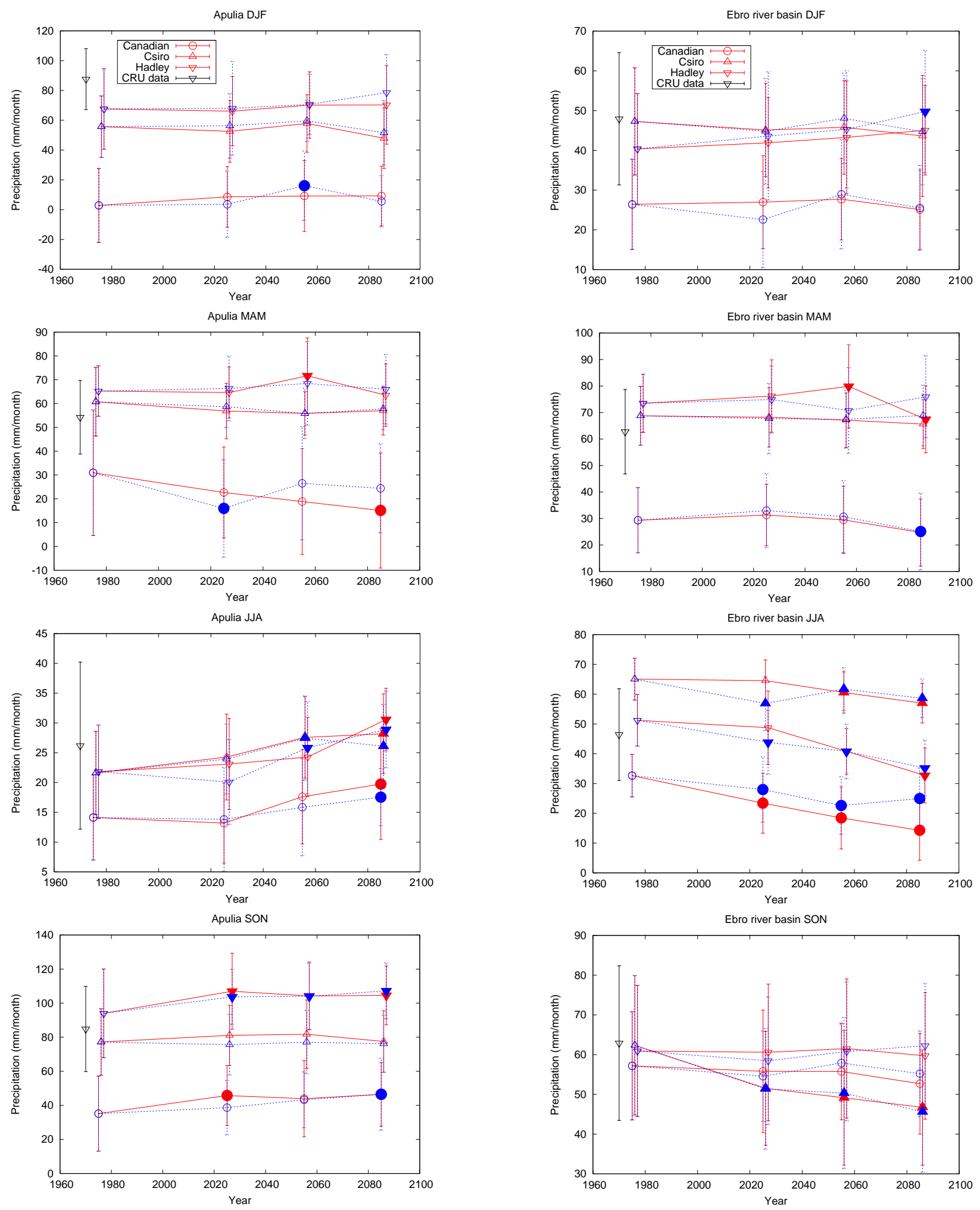

Fig. 5. Mean and standard deviation of the downscaled precipitation for the A2 (solid red lines) and B2 (dashed blue) scenario for Apulia. Circles refer to Canadian GCM, triangles to Csiro and reverse-triangles to Hadley Centre GCM. Filled symbols indicate precipitation significantly different from the CTR. The isolated triangle on the left of each plot refers to CRU data.

Fig. 6. The same as in Fig. 5 for the Ebro river basin. 

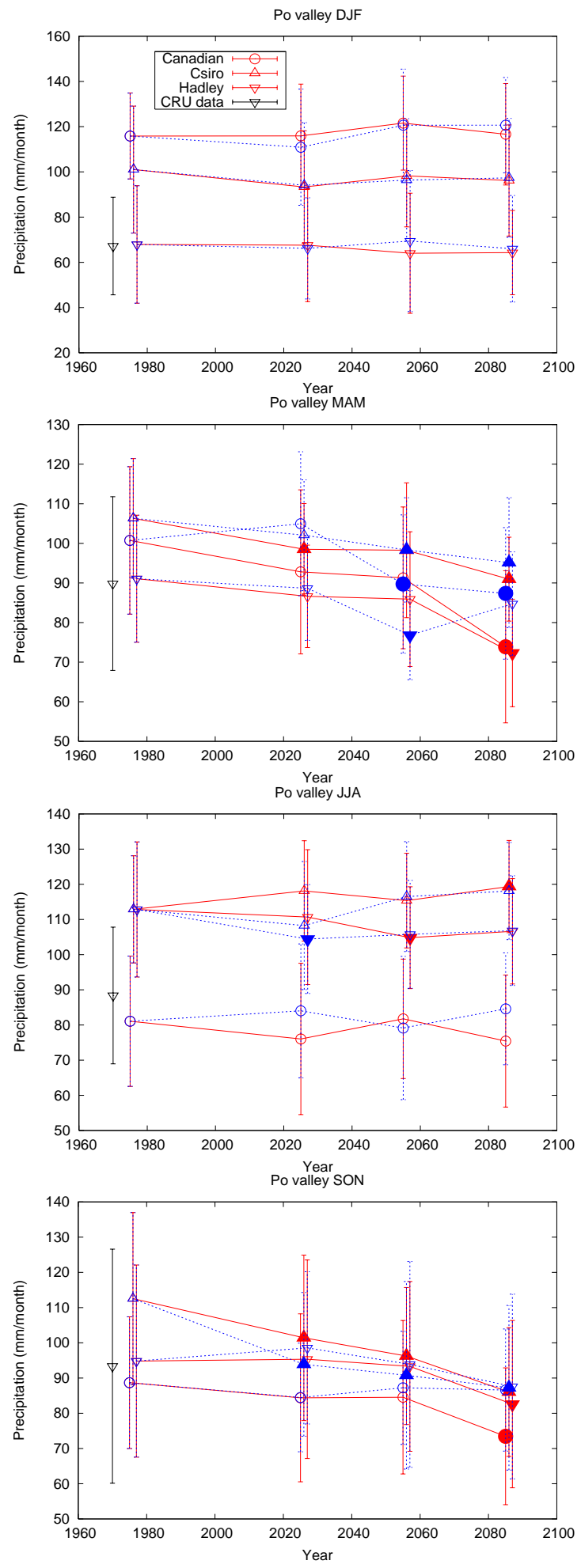

Fig. 7. The same as in Fig. 5 for the Po valley.

northern latitudes is lower than the observed values, in particular during DJF, when simulated cyclones in the Aleutinian and Icelandic region are too intense. As a consequence of the stronger intensity of the Iceland depression and of
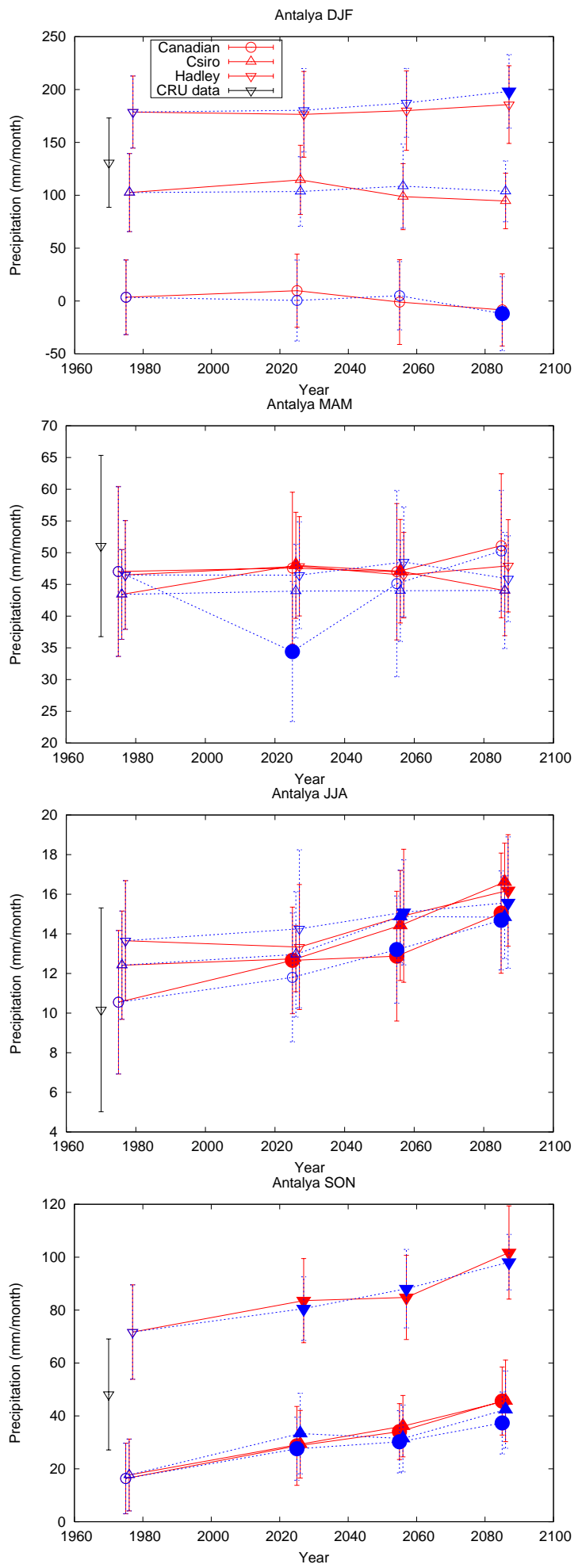

Fig. 8. The same as in Fig. 5 for the Antalya province.

the Azores anticyclone, and of their shift respectively to the south-east and over northern Africa, the model overestimates the pressure gradient over western Europe (Osborn, 2002). However, the daily variance of SLP in DJF and JJA agrees 
remarkably well with the observations, indicating a successful simulation of the surface synoptic variability (McFarlane et al., 1992).

McGregor et al. (1993); Smith (1994); Watterson et al. (1995); Gordon and O'Farrell (1997) report that the CSIROMk2 (Csiro) reproduces well the major large scale SLP features. The model has taken part in the international intercomparisons of models - PCMDI (Program for Climate Model Diagnosis and Intercomparison ${ }^{4}$ ), performing well in different regions (Lambert and Boer, 2001; Gordon et al., 2002). For what concerns the western Europe climate, the location of the Azores anticyclone and of the Iceland depression in DJF are well reproduced, although the depth of the cyclone is slightly overestimated, while a pressure trough, missing in the observations, is simulated over the central Mediterranean (Osborn, 2002).

Mean sea level pressure is generally well modeled by the HadCM3 (Hadley) in comparison with the observations, as reported in Stratton (1999); Gordon et al. (2000); Pope et al. (2000): the positioning and shape of the major equatorial low-pressure belts, subtropical highs and mid-latitude lowpressure systems is quite accurately reproduced (Johns et al., 1997) in both DJF and JJA seasons. The main systematic error is high pressure at high latitudes for most of the year, that affects both the Poles and the Icelandic low in the Northern Hemisphere. Associated with these biases, easterly biases are present in the surface winds (Pope et al., 2000). The relatively weak Icelandic low and Azores high are responsible for weak SLP gradient over western and northern Europe in DJF (Osborn, 2002), indicating insufficient propagation of storms into this region (Johns et al., 1997). Although there is good agreement between the model and observed areas of maximum high frequency variability or storm tracks in the North Pacific and Atlantic, the model variability is, however, too weak in the Northern Hemisphere in DJF and the storm tracks are displaced south and west of their observed position (Johns et al., 1997). The northward displacement of the storm track in JJA is realistically simulated in the Pacific but is too small in the Atlantic and the variability remains slightly lower than suggested by the analysis.

In conclusion, with respect to the DJF sea level pressure (SLP) climatology over Europe (Basnett and Parker, 1997; Jones et al., 1999), the large scale features are reasonably simulated by all these models, although their absolute values are sometimes in error (Osborn, 2002). The leading mode of the Atlantic-sector interannual variability, defined by the leading empirical orthogonal function (EOF) of SLP from each model, is the NAO in all cases. Projecting the observed SLP onto the simulated EOF's results in time series that closely match those of the observed leading EOF's, indicating that biases in the simulated SLP patterns are relatively unimportant.

\footnotetext{
${ }^{4}$ http://www-pcmdi.llnl.gov
}

Another approach to validate the different GCM's is to consider the downscaled precipitation observed during the CTR and compare its average value and standard deviation with the actual values reported in the CRU data for the period 1961-1990.

In Figures 5, 6, 7, and 8 also the mean and standard deviation of CRU precipitation together with the downscaled projections obtained from the GCM SLP is reported. For some runs the difference is significant (especially for the Canadian GCM) while the model HadCM3 (Hadley) model seems to capture in most cases both the average precipitation and the variance. Intermediate results are obtained by means of Csiro model.

\subsection{Climate projections}

The results of downscaling using SLP as predictor can be summarized as follows:

- Apulia: a progressive increase in Summer precipitation is observed for both SRES (note that no model is able to reproduce the large standard deviation of CRU data in Summer); the change is significant for all models in period III. No change occurs in Winter for both A2 and B2 SRES; the projections are substantially constant in Spring (only Canadian GCM for A2 SRES suggests a decrease); in Autumn Hadley Center and Canadian models indicate a significant increase of precipitation, while Csiro suggests a constant value.

- Ebro river basin: a large and significant reduction of Summer precipitation (up to $50 \%$ ) is projected by all models and for all SRES; this change is already significant in period I for all the models with the B2 SRES. In Autumn only Csiro model suggests a decrease with both scenarios. Winter precipitation generally remains constant. In Spring the Hadley center model suggests an increase in period II and a decrease in III, which is partially confirmed by Canadian model.

- Po valley: Autumn and Spring precipitation decrease for practically all SRES and models already in period I. In Winter the precipitation remains constant while Summer precipitation behaves differently depending on the model and scenario that are considered. However, the Canadian model, which better reproduces the CRU data in this area, suggests a constant value.

- Antalya province: We observe for Summer and Autumn precipitation an increase for all models and SRES. During Winter and Spring the precipitation remains constant for most of the SRES. However, in this area the computed Summer precipitation change is not convincing, because the validation of the downscaling technique gives unsatisfactory results (see Table 1). 
A quite common feature of all results is that $\mathrm{B} 2$ projections are qualitatively similar to A2 ones except that, comparing the control run with the last of the 30 -year periods, they generally present a lower change, that is particularly clear in JJA, while the differences are smaller in DJF. This is not surprising considering that in B2 SRES emissions are lower than in A2.

As previously stated, for Apulia region we also used T500 as predictor for JJA precipitation. Figure 9 shows the comparison between the projections obtained using the SLP and the T500 fields of the Hadley Centre GCM for the A2 SRES. The quantitative comparison between the two predictors is affected by the different length of the time series: the T500 time series is only 44 years long while SLP is 102 years long, and it covers the period 1901-2002. Anyway we perform the same validation procedure using T500 as predictor dividing the 44 year long series in two halves. For comparison we perform the validation using SLP as predictor only for the period covered by T500 series (notice that this time also SLP series is only 44 years long). We obtain an average error of $88 \%$ with T500 and $98 \%$ with SLP. It must be noted that these high values are due to the shortness of the series; however it is relevant that T500 leads to results comparable with SLP.

From a qualitative point of view the two predictors lead to similar increasing trends and in phase oscillations, although the changes predicted using T500 as predictor are larger. A similar agreement between the results obtained with the SLP and T500 is not present in other areas. However, the results obtained for JJA Apulia Summer precipitation with T500 are reasonable, because the computed canonical patterns are easily interpretable from a meteorological point of view (i.e. cold air advection from the north-east associated with an higher pressure over northern Europe), as shown in Fig. 4.

Finally, it is possible that the scenario circulation changes in such a way that the Summer precipitation will be determined more extensively by synoptic systems than by local convective events (of which T500 anomaly is an indicator). For these reasons, the results obtained using T500 as predictor should be considered cautiously.

\section{Conclusions}

In this paper we have compared two slightly different version of CCA for the statistical downscaling of regional precipitation. Between these methods, we have selected CCA after PCA filtering on both predictor (SLP) and predictand (seasonal precipitation). We have shown that this method is generally reliable for downscaling of seasonal precipitation in four areas of agricultural interest in the Mediterranean region: Apulia region, Ebro river basin, Po valley and Antalya province. The main exception is Summer precipitation for Antalya province, where results are unsatisfactory (the relative error is $72 \%$ ).

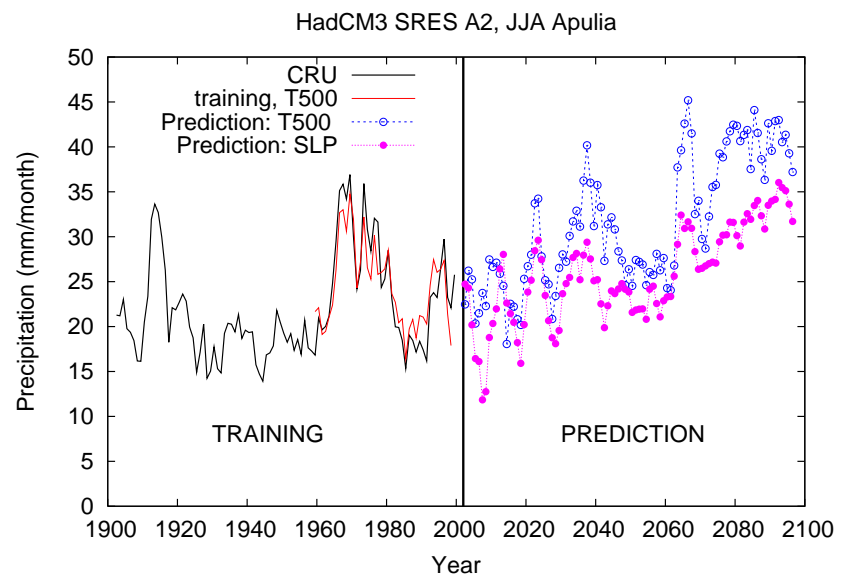

Fig. 9. Plot considers both training and projection period, separated by the vertical line at year 2002. Training: the black line refers to 5 year running average of CRU JJA data for Apulia region, while the red line is the filtered (reconstructed signal) of the same CRU data performed using the first two canonical patterns of the CCAPCAXY technique. Projection: comparison between the 5 year running average of Hadley A2 SRES downscaled projection obtained using SLP (violet) and T500 (blue) as predictor.

The strong reduction of Summer precipitation over the Ebro river basin appears clear. This is related to the stability of the downscaling procedure (mainly due to geographical and large scale circulation features) and to the agreement with the results of dynamical downscaling techniques (Giorgi et al., 2004a,b).

We obtain a significant increase for Apulia Summer precipitation. This increase is confirmed changing the predictor from SLP to T500, but it partially contrasts with the results of dynamical downscaling.

The fact that in large part of the Mediterranean basin Summer precipitation is very small, and the presence of strong uncertainties in the statistical relationship as well as in the models suggest to consider the predicted increase in Summer precipitation cautiously. Other results should be confirmed by further investigations. The decrease of precipitation in the Po valley both in Spring and Autumn contrasts with dynamical downscaling results. The increase of precipitation in the Antalya province both in Summer and especially in Autumn is very strong and common to all considered GCM's, but the large error of the method for this area, especially in Summer, reduces the confidence on these results.

In general, this study suggests smaller projected climate changes, or even sometimes with opposite sign, with respect to most dynamical models, both global (Giorgi and Lionello, 2008) and regional. In fact, as shown by the results of the PRUDENCE project (Déqué et al., 2005), also regional models agree on the Summer drying in Mediterranean sub-regions. However, the small increase of Winter 
precipitation over the Iberian Peninsula in PRUDENCE (which is in contrast with most global simulations) is in substantial agreement with the results of this statistical downscaling. Eastern Mediterranean and Middle East are outside the common area of the PRUDENCE project. Considering global projections, the southern coast of Turkey in Summer is close to a transitional area between contrasting future conditions, which in the central Mediterranean region are drier and in the Middle East are wetter than the present ones. There is no surprise that in presence of such complicated morphological features a regional downscaling may produce different results with respect to the global models.

Finally, the results of this study are based on SLP and $500 \mathrm{hPa}$ temperature. Rowell and Jones (2006) suggested, in the projected climate scenarios, that dry Summer in the Mediterranean are mainly due to low Spring soil moisture conditions leading to reduced Summer convection and to large land-sea contrast in warming leading to reduced relative humidity and precipitation over the continent. These factors are not accounted for by the downscaling techniques used in our approach and this may explain the differences with respect to the results of the dynamical models.

This study confirms the potential effectiveness of statistical downscaling methods. It also shows that climate change projections of precipitation differ among the considered areas confirming the need for downscaling techniques capable to resolve internal differences in the Mediterranean region. According to this paper the widespread reduction of precipitation in the Mediterranean region needs further investigation to be confirmed. Projecting drier conditions for the whole Mediterranean area is likely correct at broad basin scale, but should not be generalized for small areas, especially close to its border, where the downscaling exercise of this study shows the potential for different climate change signals and where specific studies are needed.

The present research is the first step in order to better understand the impact of climate change on agricultural systems typical of Mediterranean region. A forthcoming paper will cover more directly the impact of these changes on crop growth.

\section{Appendix A}

\section{The Canonical Correlation Analysis}

In this section we briefly review the statistical technique used in this paper. The notation is the same as von Storch and Zwiers (1999). CCA searches couples of patterns, the canonical conjugated patterns, or briefly canonical patterns (CP), made up of a vector for the predictor $f_{x}$ and another for the predictand $f_{y}$. We defined the canonical conjugated coordinates (CCC's), $\beta_{x}(t)$ and $\beta_{y}(t)$, as

$\beta_{x}(t)=\sum_{k} \boldsymbol{X}_{k}(t) f_{x, k} \equiv\left\langle\boldsymbol{X}(t), f_{x}\right\rangle$,

$\beta_{y}(t)=\left\langle\boldsymbol{Y}(t), f_{y}\right\rangle$,

where \langle\rangle denotes the (spatial) scalar product between two vectors and $\boldsymbol{X}(t), \boldsymbol{Y}(t)$ are the vectors of predictor and predictand at time $t$, respectively. It is important to note that CCA must be applied to the difference between real observations and their time averaged value $\overline{\mathcal{X}}$ and $\overline{\mathcal{Y}}$, thus $\boldsymbol{X}(t)$ and $\boldsymbol{Y}(t)$ are connected to the observed values of predictor $\mathcal{X}(t)$ and predictand $\mathcal{Y}(t)$ according to

$$
\begin{aligned}
& \boldsymbol{X}(t)=\mathcal{X}(t)-\frac{1}{\tau} \sum_{t=1}^{\tau} \mathcal{X}(t)=\mathcal{X}(t)-\overline{\mathcal{X}} \\
& \boldsymbol{Y}(t)=\mathcal{Y}(t)-\frac{1}{\tau} \sum_{t=1}^{\tau} \mathcal{Y}(t)=\mathcal{Y}(t)-\overline{\mathcal{Y}} .
\end{aligned}
$$

CCA looks for $f_{x}$ and $f_{y}$ that maximize the correlation

$\rho_{x y}=\left(\beta_{x}(t), \beta_{y}(t)\right) \equiv \frac{1}{\tau} \sum_{t=1}^{\tau} \beta_{x}(t) \beta_{y}(t)$

under the constraint that

$\operatorname{Var}\left(\beta_{x}(t)\right)=\operatorname{Var}\left(\beta_{y}(t)\right)=1$

with Var denoting the time variance and $\tau$ the total number of measurements in time. It can be proven (von Storch and Zwiers, 1999) that the CP's are the solution of an eigenvalue problem with the eigenvalue equal to the square of the correlation $\rho_{x y}$ between $\beta_{x}(t)$ and $\beta_{y}(t)$.

The CCA technique is applied in several statistical problems. To perform statistical downscaling we use this technique to derive from a large scale field (e.g. SLP) - the predictor - a regional scale field (e.g. precipitation) - the predictand - which is not adequately described in climatic projections of GCM's. To obtain the downscaled value of the predictand we first calculate the difference between the climatic projection of the predictor $\tilde{\mathcal{X}}(t)$ and the time averaged value of observed predictor, according to

$\tilde{\boldsymbol{X}}(t)=\tilde{\mathcal{X}}(t)-\overline{\mathcal{X}}$.

Then we expand $\tilde{\boldsymbol{X}}(t)$ on a suitable number $k$ of CP's,

$\tilde{\boldsymbol{X}}(t) \simeq \sum_{i=1}^{k} \tilde{\beta}_{x}^{(i)}(t) F_{x}^{(i)}$

where

$\tilde{\beta}_{x}^{(i)}(t)=\left\langle\tilde{\boldsymbol{X}}, f_{x}^{(i)}\right\rangle$,

$F_{x, y}^{(i)}$ are the adjoint of $f_{x, y}^{(i)}$ fulfilling

$F_{x}^{(i)}=\Sigma_{x x} f_{x}^{(i)}, F_{y}^{(i)}=\Sigma_{y y} f_{y}^{(i)}$, 
where

$\Sigma_{x x, k j}=\frac{1}{\tau} \sum_{t=1}^{\tau} \boldsymbol{X}_{k}(t) \boldsymbol{X}_{j}(t)$

$\Sigma_{y y, k j}=\frac{1}{\tau} \sum_{t=1}^{\tau} \boldsymbol{Y}_{k}(t) \boldsymbol{Y}_{j}(t)$.

$F_{x}^{(i)}\left(F_{y}^{(i)}\right)$ represents the value of variable $\boldsymbol{X}(t)(\boldsymbol{Y}(t))$ when the CCC $\beta_{x}^{(i)}=1\left(\beta_{y}^{(i)}=1\right)$. The downscaled variables $\tilde{\mathcal{Y}}(t)$ is obtained with the expansion

$\tilde{\mathcal{Y}}(t) \simeq \overline{\mathcal{Y}}+\sum_{i=1}^{k} \tilde{\beta}_{x}^{i}(t) \rho_{x y}^{i} F_{y}^{i}$.

where, as before, $\overline{\mathcal{Y}}$ is the time averaged value of observed predictands. There is no strict criterium for choosing the suitable number of patterns $k$ in the expansions (A6), (A10) (von Storch and Zwiers, 1999). Here only those patterns with eigenvalues significantly different from the lower ones have been retained.

This statistical model is based on the hypothesis that linear correlation $\rho_{x y}^{(i)}$ between different CCC's, is valid also in the scenario provided by the runs of the GCM.

Very often CCA technique is not applied directly but on a previously filtered dataset. The filtering is performed using the Principal Component Analysis in order to eliminate small scale noise from predictors, predictands or both.

Another important technical detail in statistical downscaling is the algorithm needed to project GCM projections on Canonical Correlation Pattern. Indeed it is necessary to interpolate the data from the GCM grid to the predictor one. In our cases the two grids have comparable resolution so we use a quite simple method. For each point of predictor grid of coordinates $\left(x_{\mathrm{p}}, y_{\mathrm{p}}\right)$ we choose the 4 nearest points of the GCM grid. These points are the vertices of a rectangle with coordinates $\left(x_{i}, y_{i}\right) i=1,2,3,4$. We thus obtain the values of a field $f(x, y)$ in $\left(x_{\mathrm{p}}, y_{\mathrm{p}}\right)$ with a bilinear form given by

$$
\begin{aligned}
f\left(x_{\mathrm{p}}, y_{\mathrm{p}}\right)= & f_{11}+\frac{x_{\mathrm{p}}-x_{1}}{x_{2}-x_{1}}\left(f_{21}-f_{11}\right)+\frac{y_{\mathrm{p}}-y_{1}}{y_{2}-y_{1}}\left(f_{12}-f_{11}\right) \\
& +\left(\frac{y_{p}-y_{1}}{y_{2}-y_{1}}\right)\left(\frac{x_{p}-x_{1}}{x_{2}-x_{1}}\right)\left(f_{22}-f_{12}-f_{21}+f_{11}\right)
\end{aligned}
$$

where $f_{i j}=f\left(x_{i}, y_{j}\right)$.

Acknowledgements. This work has been funded by FISR CLIMESCO project: Evoluzione dei Sistemi Colturali a seguito dei Cambiamenti Climatici, contract no. 285-20.02.2006.

Edited by: M.-C. Llasat

Reviewed by: two anonymous referees

\section{References}

Alpert, P., Baldi, M., Ilani, R., Krichak, S., Price, C., Rodó, X., Saaroni, H., Ziv, B., Kishcha, P., Barkan, J., Mariotti, A., and Xoplaki, E.: Relations between climate variability in the Mediterranean region and the tropics: ENSO, South Asian and African Monsoons, Hurricanes and Saharan Dust, in: Mediterranean Climate Variability, edited by: Lionello, P., Malanotte-Rizzoli, P., and Boscolo, R., Elsevier, Amsterdam, Netherlands, 149-177, 2006.

Ansell, T. J., Jones, P. D., Allan, R. J., Lister, D., Parker, D. E., Brunet, M., Moberg, A., Jacobeit, J., Brohan, P., Rayner, N A., Aguilar, E., Alexandersson, H., Barriendos, M., Brandsma, T., Cox, N. J., Della-Marta, P. M., Drebs, A., Founda, D., Gerstengarbe, F., Hickey, K., Jónsson, T., Luterbacher, J., Nordli, Ø., Oesterle, H., Petrakis, M., Philipp. A., Rodwell, M. J., Saladie, O., Sigro, J., Slonosky, V., Srnec, L., Swail, V., GarcíaSuárez, A. M., Toumenvirta, H., Wang, X., Wanner, H., Werner, P., Wheeler, D., and Xoplaki, E.: Daily mean sea level pressure reconstructions for the European - North Atlantic region for the period 1850-2003, J. Climate, 19, 2717-2742, 2006.

Basnett, T. A. and Parker, D. E.: Development of the Global Mean Sea Level Pressure data Set GMSLP2, CRTN 79, Hadley Centre for Climate Prediction and Research, London, 1997.

Brunetti, M., Maugeri, M., Monti, F., and Nanni, T.: Changes in daily precipitation frequency and distribution in Italy over the last 120 years, J. Geophys. Res.-Atmos., 109, D05102, doi:10.1029/2003JD004296, 2004.

Brunetti, M., Maugeri, M., Monti, F., and Nanni, T.: Temperature and precipitation variability in Italy in the last two centuries from homogenized instrumental time series, Int. J. Climatol., 26, 345381, 2006.

Corte-Real, J., Zhang, X., and Wang, X.: Downscaling GCM information to regional scales: a non-parametric multivariate regression approach, Clim. Dynam., 11, 413-424, 1995.

Déqué, M., Jones, R. G., Wild, M., Giorgi, F., Christensen, J. H., Hassell, D. C., Vidale, P. L., Rockel, B., Jacob, D., Kjellström, E., de Castro, M., Kucharski, F., and van den Hurk, B.: Global high resolution vs. regional climate model climate change scenarios over Europe: Quantifying confidence level from PRUDENCE results, Clim. Dynam., 25, 653-670, 2005.

Flato, G. M., Boer, G. J., Lee, W. G., McFarlane, N. A., Ramsden, D., Reader, M. C., and Weaver, J. A.: The Canadian Centre for Climate Modelling and Analysis global coupled model and its climate, Clim. Dynam., 16, 451-467, 2000.

Flato, G. M. and Boer, G. J.: Warming Asymmetry in Climate Change Simulations, Geophys. Res. Lett., 28, 195-198, 2001.

Giorgi, F., Bi, X., and Pal, J. S.: Mean, interannual variability and trends in a regional climate change experiment over Europe. I Present-day climate (1961-1990), Clim. Dynam., 22, 733-756, 2004.

Giorgi, F., Bi, X., and Pal, J. S.: Mean, interannual variability and trends in a regional climate change experiment over Europe. II: climate change scenarios (2071-2100), Clim. Dynam., 23, 839858, 2004.

Giorgi, F.: Climate change Hot-spots, Geophys. Res. Lett., 33, L08707, doi:10.1029/2006GL025734, 2006.

Giorgi, F., and Lionello, P.: Climate Change Projections for the Mediterranean Region, Global Planet. Change, 63, 90-104, 2008. 
Gonzalez-Hidalgo, J. C., Lopez-Bustins, J.-A., Stepanek, P., Martin-Videb, J., and de Luisa, M.: Monthly precipitation trends on the Mediterranean fringe of the Iberian Peninsula during the second-half of the twentieth century (1951-2000), Int. J. Climatol., 29, 1415-1429, 2009.

Goodess, C.: STARDEX detailed report, available at: http://www. cru.uea.ac.uk/projects/stardex/ (last acces: 19 July 2010), 2005.

Gordon, H. B. and O'Farrell, S. P.: Transient climate change in the CSIRO coupled model with dynamic sea ice, Mon. Weather Rev., 125, 875-907, 1997.

Gordon, C., Cooper, C., Senior, C., Banks, H., Gregory, J., Johns, T., Mitchell, J., and Wood, R.: The simulation of SST, sea ice extents and ocean heat transports in a coupled model without flux adjustments, Clim. Dynam., 16, 147-168, 2000.

Gordon, H. B., Rotstayn, L. D., McGregor, J. L., Dix, M. R., Kowalczyk, E. A., O'Farrell, S. P., Waterman, L. J., Hirst, A. C., Wilson, S. G., Collier, M. A., Watterson, I. G., and Elliott, T. I.: The CSIRO Mk3 Climate System Model, CSIRO Atmospheric Research Technical Paper n. 60, 2002.

Hertig, E. and Jacobeit, J.: Assessments of Mediterranean precipitation changes for the 21 st century using statistical downscaling techniques, Int. J. Climatol., 28, 1025-1045, 2008.

Hollander, M. and Wolfe, D. A.: Nonparametric Statistical Methods, John Wiley and Sons, New York, 1973.

Hurrell, J. W.: Decadal trends in the North Atlantic Oscillation: Regional temperature and precipitation, Science, 269, 676-679, 1995.

IPCC: Climate Change: The Scientific Basis, edited by: Houghton, J. T., Ding, Y., Griggs, D. J., Noguer, M., van der Linden, P. J., and Xiaosu, D., Cambridge University Press, 2001.

Jacobeit, J., Dünkeloh, A., and Hertig E.,: Mediterranean rainfall changes and their causes, in: Enough Water for All?, edited by: Lozan, J. L., Graß, H., Hupfer, P., Menzel, L., and Schönwiese, C. D., Wisseshaftliche Auswertungen, Hamburg, 195-199, 2007.

Johns, T. C., Carnell, R. E., Crossley, J. F., Gregory, J. M., Mitchell, J. F. B., Senior, C. A., Tett, S. F. B., and Wood, R. A.: The second Hadley Centre coupled ocean-atmosphere GCM: model description, spinup and validation, Clim. Dynam., 13, 103-134, 1997.

Jones, P. D., Davies, T. D., Lister, D. H., Slonosky, V., Jónsson, T., Bärring, L., Jónsson, P., Maheras, P., Kolyva-Machera, F., Barriendos, M., Martin-Vide , J., Rodriguez, R., Alcoforado, M. J., Wanner, H., Pfister, C., Luterbacher, J., Rickli, R., Schuepbach, E., Kaas, E., Schmith, T., Jacobeit, J., and Beck, C.: Monthly Mean Pressure Reconstructions for Europe for the 1870-1995 Period, Int. J. Climatol., 19, 347-364, 1999.

Lambert, S. J. and Boer, G. J.: CMIP1 evaluation and intercomparison of coupled climate models, Clim. Dynam., 17, 83-106, 2001.

Lionello, P., Elvini, E., and Nizzero, A.: Ocean waves and storm surges in the Adriatic Sea: intercomparison between the present and doubled CO2 climate scenarios, Clim. Res., 23, 217-231, 2003.

Lionello, P., Malanotte-Rizzoli, P., and Boscolo R.: Mediterranean Climate Variability, Elsevier, Amsterdam, Netherlands, ISBN: 0444-52170-4, 2006.

McFarlane, N. A., Boer, G. J., Blanchet, J.-P. , and Lazare, M.: The Canadian Climate Centre second-generation general circulation model and its equilibrium climate, J. Climate, 5, 1013-1044,
1992.

McGregor, J. L., Gordon, H. B., Watterson, I. G., Dix, M. R., and Rotstayn, L. D.: The CSIRO 9-level atmospheric general circulation model, CSIRO Division of Atmospheric Res., Tech. Paper n. 26, 1993.

Mitchell, T. D. and Jones, P. D.: An improved method of constructing a database of monthly climate observations and associated high-resolution grids, Int. J. Climatol., 25, 693-712, 2005.

Osborn, T. J.: The winter North Atlantic Oscillation: roles of internal variability and greenhouse gas forcing, CLIVAR Exchanges, 25, 54-58, 2002.

Pope, V. D., Galloni, M. L., Rowntree, P. R., and Stratton, R. A.: The impact of new physical parametrizations in the Hadley Centre climate model: HadAM3, Clim. Dynam., 16, 123-146, 2000.

Randall, D. A., Wood, R. A., Bony, S., Colman, R., Fichefet, T., Fyfe, J., Kattsov, V., Pitman, A., Shukla, J., Srinivasan, J., Stouffer, R. F., Sumi, A., and Taylor, K. E.: Climate Models and Their Evaluation, in Climate Change 2007: The Physical Science Basis, in: Contribution of Working Group I to the Fourth Assessment Report of the Intergovernmental Panel on Climate Change, edited by: Solomon, S., Qin, D., Manning, M., Chen, Z., Marquis, M., Averyt, K. B., Tignor, M., and Miller, H. L., Cambridge University Press, Cambridge, United Kingdom and New York, NY, USA, 2007.

Rowell, D. P. and Jones, R. G.: Causes and uncertainty of future summer drying over Europe, Clim. Dynam., 27, 281-299, 2006.

Saaroni, H. and Ziv, B.: Summer rain episodes in a Mediterranean climate, the case of Israel: Climatological-dynamical analysis, Int. J. Climatol., 20, 191-209, 2000.

Smith, I. N.: A GCM simulation of global climatic trends: 19501988, J. Climate, 7, 732-744, 1994.

Stratton, R. A.: A high resolution AMIP integration using the Hadley Centre model HadAM2b, Clim. Dynam., 15, 9-28, 1999.

Trigo, R. M. and Palutikof, J. P.: Precipitation Scenarios over Iberia: A Comparison between Direct GCM Output and Different Downscaling Techniques, J. Climate, 14, 4422-4446, 2001.

Trigo, R., Xoplaki, E., Zorita, E., Lutherbacher, J., Krichak, O., Alpert, P., Jacobeit, J., Saenz, J., Fernandez, J., GonzálesRouco, J., García-Herrera, R., Rodo, X., Brunetti, M., Nanni, T., Maugeri, M., Turkes, M., Gimeno, L., Ribera, P., Brunet, M., Trigo, I. F., Crepon, M., and Mariotti, A.: Relations between variability in the Mediterranean region and mid-latitude variability, in: Mediterranean Climate Variability, edited by: Lionello, P., Malanotte-Rizzoli, P., and Boscolo, R., Elsevier, Amsterdam, Netherlands, 179-226, 2006.

Uppala, S. M., KÅllberg, P. W., Simmons, A. J., Andrae, U., Da Costa Bechtold, V., Fiorino, M., Gibson, J. K., Haseler, J., Hernandez, A., Kelly, G. A., Li, X., Onogi, K., Saarinen, S., Sokka, N., Allan, R. P., Andersson, E., Arpe, K., Balmaseda, M. A., Beljaars, A. C. M., Van De Berg, L., Bidlot, J., Bormann, N., Caires, S., Chevallier, F., Dethof, A., Dragosavac, M., Fisher, M., Fuentes, M., Hagemann, S., Hólm, E., Hoskins, B. J., Isaksen, L., Janssen, P. A. E. M., Jenne, R., Mcnally, A. P., Mahfouf, J.-F., Morcrette, J.-J., Rayner, N. A., Saunders, R. W., Simon, P., Sterl, A., Trenberth, K. E., Untch, A., Vasiljevic, D., Viterbo, P., and Woollen, J.: The ERA-40 re-analysis, Q. J. Roy. Meteor. Soc., 131, 2961-3012, 2005. 
Vasiliades, L., Loukas, A., and Patsonas, G.: Evaluation of a statistical downscaling procedure for the estimation of climate change impacts on droughts, Nat. Hazards Earth Syst. Sci., 9, 879-894, doi:10.5194/nhess-9-879-2009, 2009.

von Storch, H., Zorita, E., and Cubash, U.: Downscaling of global Change Estimates to Regional Scales: An application to Iberian Rainfall in Wintertime, J. Climate, 6, 1161-1171, 1993.

von Storch, H. and Zwiers, F. W.: Statistical Analysis in Climate Research, Cambridge University Press, Cambridge, UK, 1999.

Xoplaki, E.: Climate variability over the Mediterranean, Ph.D. thesis, University of Bern, Switzerland, http://sinus.unibe.ch/klimet/ docs/phd_xoplaki.pdf (last access: 19 July 2010), 2002.
Xoplaki, E., González-Rouco, F., Luterbacher, J., and Wanner, H.: Wet season Mediterranean precipitation variability: influence of large-scale dynamics and trends, Clim. Dynam., 23, 63-78, 2004.

Watterson, I. G., Dix, M. R., Gordon, H. B., and McGregor, J. L.: The CSIRO 9-level atmospheric general circulation model and its equilibrium present and doubled $\mathrm{CO}_{2}$ climates, Aust. Meteorol. Mag., 44, 111-125, 1995.

Zorita, E. and von Storch, H.: The analog method as a simple Statistical Downscaling Technique: Comparison with More Complicated Methods, J. Climate, 12, 2474-2489, 1999. 